International Journal of Engineering \& Technology, $7(2.1)(2018) 69-74$
International Journal of Engineering \& Technology
Website: www.sciencepubco.com/index.php/IJET
Research Paper

\title{
Road safety audit: a case study on NH-65
}

\author{
Tummala Bharat Kumar', Chukkapalli Jeswanth Chowdary ${ }^{2}$ \\ 1,2 Under graduate student, Civil Engineering Department, Velagapudi Ramakrishna Siddhartha Engineering College, \\ Vijayawada, Andhra Pradesh, India \\ *Corresponding author E-mail: tbharatkumar96@gmail.com
}

\begin{abstract}
In India there is road network of 33 lakh kilometres of which nearly $65 \%$ of the cargo activity and $80 \%$ of traveller movement is on the road networks. National Highways constitute around $1.7 \%$ of the road network but carry about $40 \%$ of the aggregate road traffic. Number of vehicles has been increasing at a normal pace of $10.16 \%$ for every annum in the course of the most recent five years. Road safety audit is the formal methodology for getting accident potential and safety potential in the development of new road schemes and the schemes for the improvement and maintenance of the existing road facilities. Accident prevention and accident reduction are the two main strategies in the road safety. In this case study we analyse the NH-65 which is the major highway connecting VIJAYAWADA and HYDERABAD from the 270thKM to 247th KM. The highway carries considerable amount of traffic throughout the day and it has number of conflict points such as villages, industries. Detailed analysis of NH-65 will be carried out from the point of view of safety and geometric design aspects will be performed. This paper aims to identify deficiencies, improving design aspects, enhancing credibility of the roads.
\end{abstract}

Keywords: Accident, improving design aspects, road safety.

\section{Introduction}

Road safety audit is comparatively an extraordinary tool for the improvement of road safety and to recognize potentially dangerous areas, includes on highway and propose remedial measures. [4] RSA Definition: It is a systematic approach for evaluating of new and existing roads by an independent team at different stages of planning, design, construction, operation and maintenance to achieve accident free roads and to increase overall safety performance. JSRPRCD [2012]: defined road safety audit as formal procedure for assessing accident potential \& safety performance in the provision of new road as well as maintenance, improvement, rehabilitation of existing roads. AUSTROADS [2002]: describes it is a formal examination of a future road or traffic project or an existing road, in which an independent, qualified team report on the projects crash potential and safety performance. ADB [2003]: defined RSA as systematic procedure for accessing the road safety of roads and road schemes

\subsection{Objectives of the study}

- Identify designing imperfections and recommend intercessions.

- Identification of accident prone regions on the highway.

- To study about the impact of roadway geometrics and traffic conditions on the highway. [6]
In this paper it is expected to assess Road Safety of National Highway [NH-65, previously NH-9] of India and will concentrate on assessing the advantages of the proposed activities that have exuded from lacks recognized through the review procedure. [4]

\subsection{Site location}

The site is from $247.650 \mathrm{~km}$ to $270.340 \mathrm{~km}$ i.e., from donabanda to neelima theatre at bhavanipuram, Vijayawada. The selected highway stretch has been studied for the safety aspect. The important areas on the survey area are Gollapudi, Ibrahimapatnam on the NH-65 in the Andhra Pradesh, India. The highway passes through a level and moving landscape for the most part rural, urban settlement land and stone crusher plants. The location map, route map and terrain map of the study area are shown in Figure 1, Figure 2 and Figure 3 respectively. The National Highway- 65 is built under BOT [Build-Operate-Transfer] model and began its commercial operations from 09 -sept-2004.

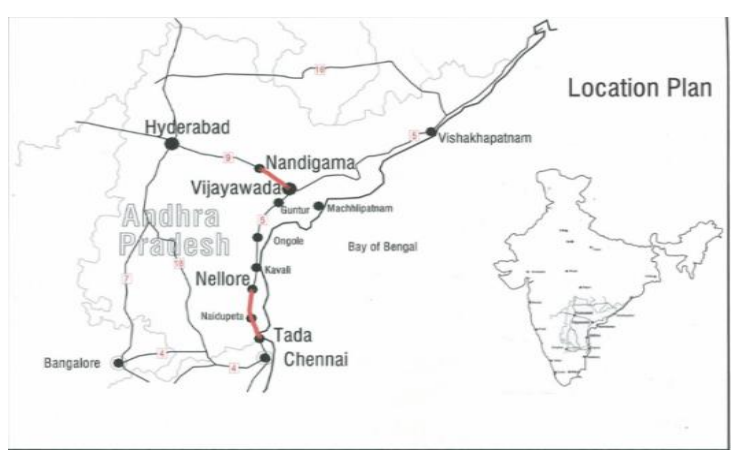

Fig.1: route map of NH-65. 


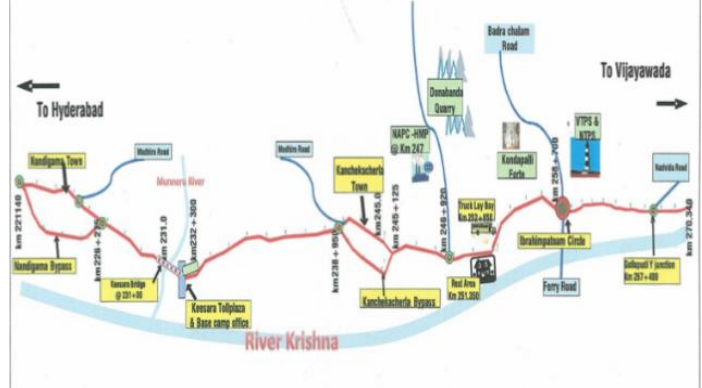

Fig.2: Key plan of the NH-65.

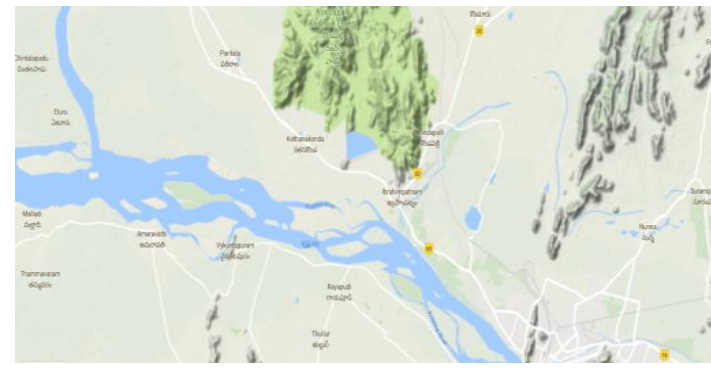

Fig.3: Showing the TERRAIN MAP of surveyed area

Source: Google maps.

\subsection{Salient features of the highway:}

The width of main carriageway is of $7.00 \mathrm{~m}$ with $2.00 \mathrm{~m}$ earthen shoulder on both left and right carriage way of the highway. The width median is $4.5 \mathrm{~m}$ and raised type in general. Road infrastructures details are as under,

$\begin{array}{ll}\text { MajorJunctions } & : 07 \text { number } \\ \text { Major Bridges } & : 02 \text { number } \\ \text { Minor Bridges } & : 05 \text { number } \\ \text { Culverts } & : 86 \text { number } \\ \text { Truck lay bays } & : 02 \text { number } \\ \text { Bus lay bays } & : 34 \text { number } \\ \text { Industries/institutions } & : 53 \text { number } \\ \text { T-junctions } & : 16 \text { number } \\ \text { Intersections } & : 2 \text { number } \\ \text { Y-junctions } & : 01 \text { number } \\ \text { Gap in median } & : 22 \text { number } \\ \text { Road curves } & : 91 \text { number } \\ \text { Petrol bunks } & : 12 \text { number } \\ \text { Pilgrimage } & : 17 \text { number } \\ \text { Road intersections } & : 185 \text { number }\end{array}$

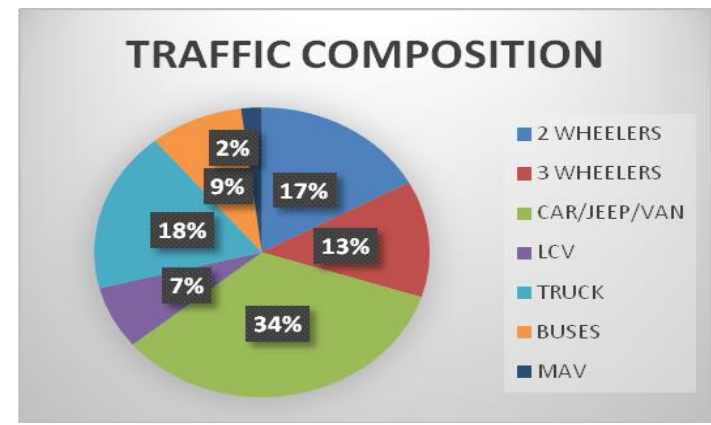

Fig.4: showing the traffic composition on NH-65.

\section{Accident data}

The accident data is collected from the national highway authorities from stretch Vijayawada to Nandigama. The data collected is for the period 2008-2017[October]. Principle perception from the analysis of the gathered accident data was that it gave an opinion of under-reporting. Real figures may be much more. It is moreover noticed that minor accidents were overlooked by and where as severe accidents involving death or severe injuries were frequently reported.

Table-1: Accident details

\begin{tabular}{cccccc}
\hline \multicolumn{5}{c}{ DETAILS OF ACIDENTS DURING DAY TIME AND NIGHT } \\
& \multicolumn{5}{c}{$\begin{array}{c}\text { Details of accident victims } \\
\text { TIME }\end{array}$} \\
\cline { 4 - 6 } Year & $\begin{array}{c}\text { Day } \\
\text { time }\end{array}$ & $\begin{array}{c}\text { Night } \\
\text { time }\end{array}$ & Fatal & Serious & minor \\
& 88 & 29 & 39 & 75 & 95 \\
2008 & 60 & 27 & 31 & 58 & 66 \\
2009 & 62 & 40 & 37 & 46 & 105 \\
2010 & 81 & 68 & 33 & 43 & 160 \\
2012 & 145 & 116 & 53 & 118 & 194 \\
2013 & 125 & 121 & 44 & 125 & 234 \\
2014 & 120 & 122 & 39 & 112 & 178 \\
2015 & 129 & 92 & 37 & 87 & 192 \\
2016 & 123 & 94 & 58 & 82 & 216 \\
$2017[$ October] & 105 & 74 & 33 & 72 & 180 \\
\hline
\end{tabular}

Source: Accident data collected from NHAI

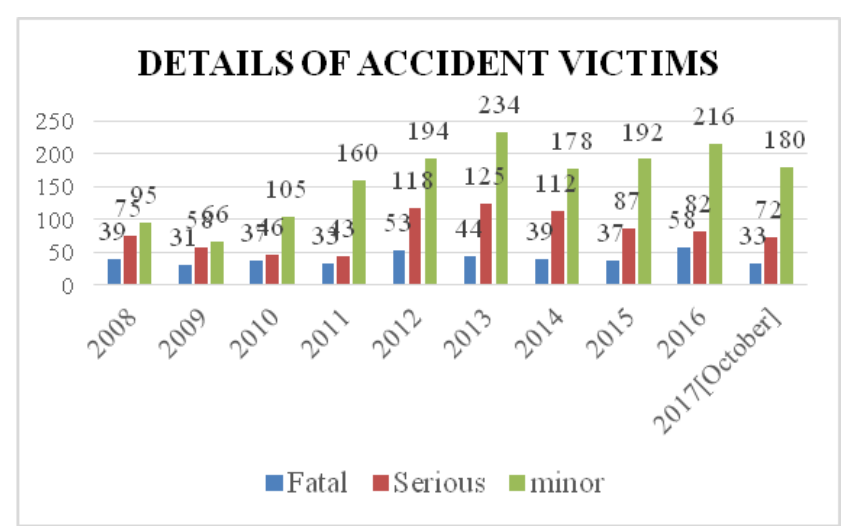

Fig.5: graph showing the accident's severity.

From the figure- 5 we can notie the increase in the rate of accidents is noticed from 2008 to 2013 and there is decrease in 2014 and there is increase from 2015 to 2017 [october] and the necessary measures has to be taken to rectify the defects on the highway.From the figure- 6 we can notice that accidents occurs on the day time are more when compared to night time. The accident rate can be decreased at night time by providing illumination at the villages, industries/institutions

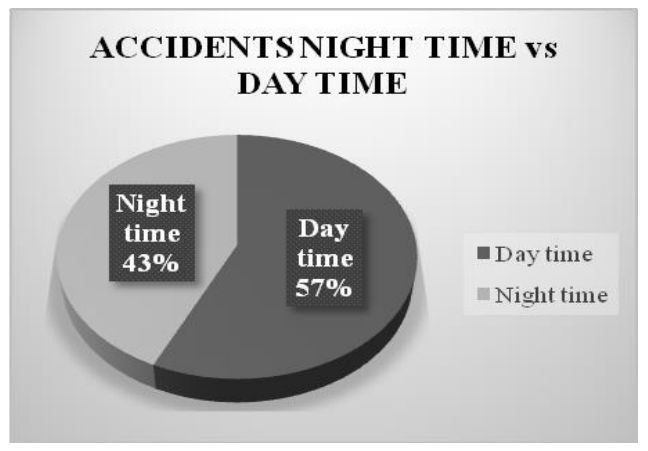

Fig.6: accidents occurring night time v/s day time. 


\section{Design aspects and general observations}

\subsection{Crash barrier location}

The crash barriers are to be provided on banks whose height difference is greater than $3.0 \mathrm{~m}$, they should be placed at the major and minor bridge approaches and also at sharp curves. There shouldn't be space between metallic crash barrier and rigid concrete crash barrier. [1]

\subsection{Central lightening arrangement}

Adequate lighting arrangement should be provided at-grade roads for the nearby village and town boundaries. Provision of high mast lighting at all the minor and major intersections of the national highway for the safe motion of vehicles and also for pedestrians during the night time.

\subsection{Road marking}

Road markings are to be properly laid on the carriage way for controlling, warning, guiding and informing the road users. [3]

\subsection{Pedestrian facility}

Raised foot path should be properly maintained in the nearby village area and towns for safety of pedestrians. Provision of pedestrian guardrail on the raised foot path on the sides of either of the carriageway particularly at the bus stops and bus bays for the length not less than $20 \mathrm{~m}$ for safety of pedestrians where their activity is high and also the provision facilities for differently abled persons should be done.

\subsection{Truck lay bay and Bus bay}

Informatory sign boards should be kept in front of truck lay and bus bay. Proper lane marking need to be carried out. Raised pedestrian footpath has to be constructed for safety of passengers. Proper transition lane should be provided and facilities for the differently abled people has to be provided.

\subsection{Median and islands}

The median and islands are to be raised at least to a height of $300 \mathrm{~mm}$ by using kerb stones and the gap has to be filled by the locally available material for the plantation along the median.

\subsection{Service roads}

Service Roads has to be developed in the areas which have high urban area such that local traffic can be separated from highway traffic. Appropriate flaring at beginning and ending of service roads should be provided. Proper road signs should be kept at all flaring areas. Proper chevron board marking should be provided at separator between main highway and service road. Hazard board marking should be kept at beginning of the divider.

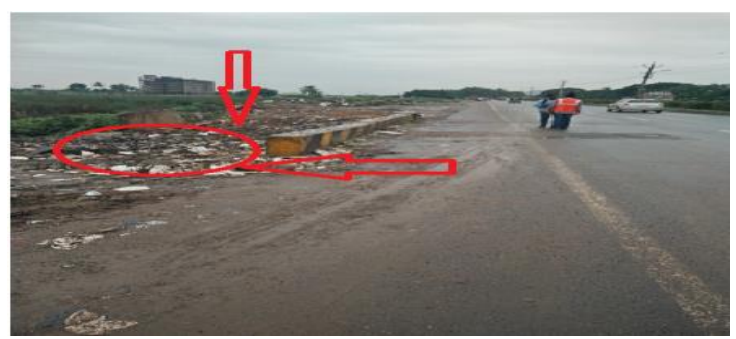

Fig.7: at chainage: $258.220 \mathrm{~km} \mathrm{RCW.}$

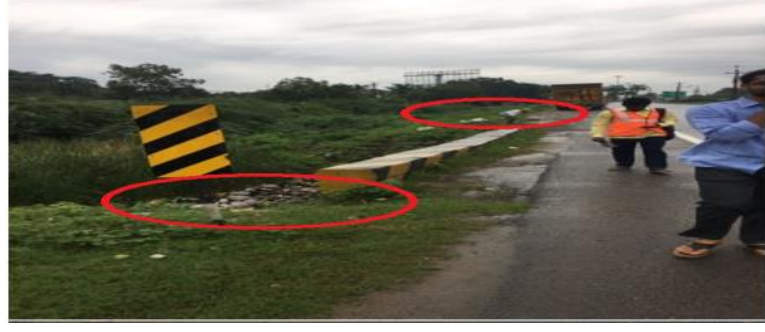

Fig.8: at chainage: $266.500 \mathrm{~km} \mathrm{LCW.}$

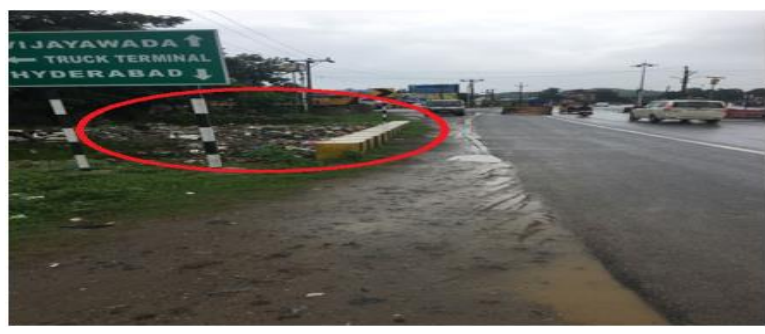

Fig.9: at chainage: $256.720 \mathrm{~km} \mathrm{LCW.}$

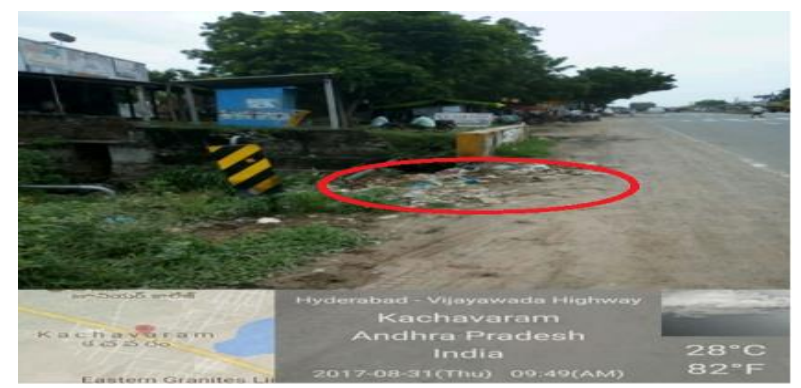

Fig.10: at chainage: $249.756 \mathrm{~km} \mathrm{LCW.}$

From the figures $7,8,9,10$ the waste is being dumped by the surrounding villages people at the culverts which can cause the blockade of the water at the culvert.

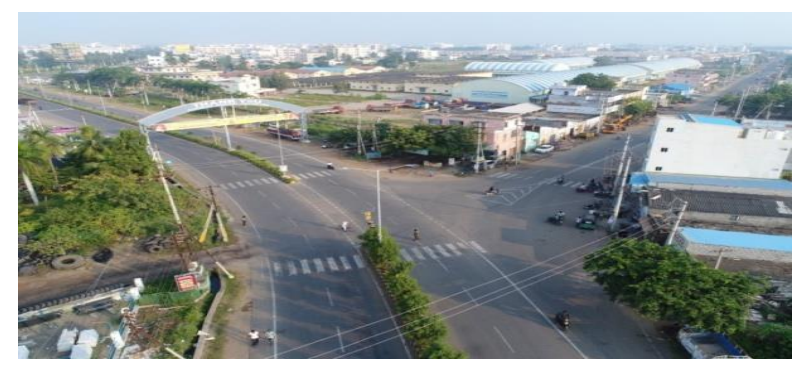

Fig.11: at chainage: $268.671 \mathrm{~km}$.

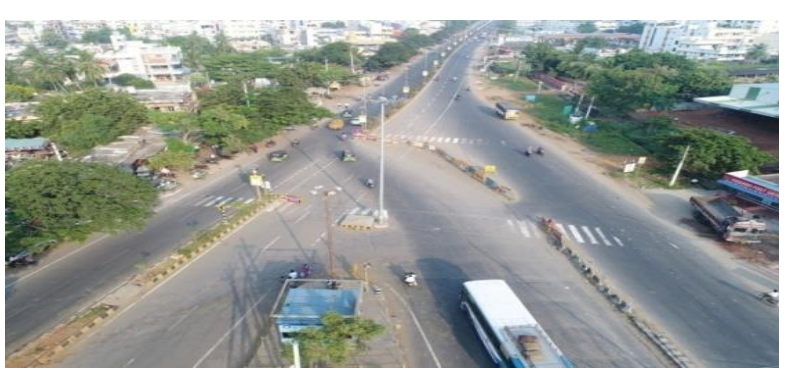

Fig.12: at chainage:267.407km.

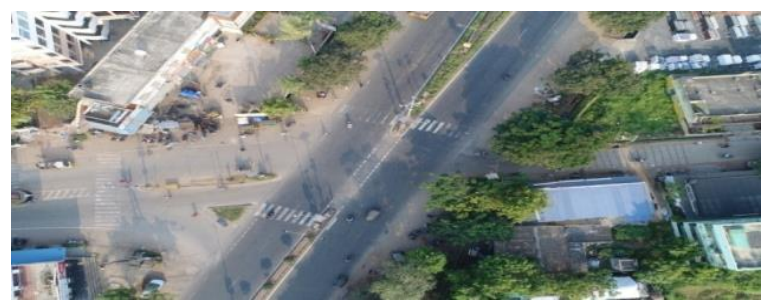

Fig.13: at chainage:266.848km. 


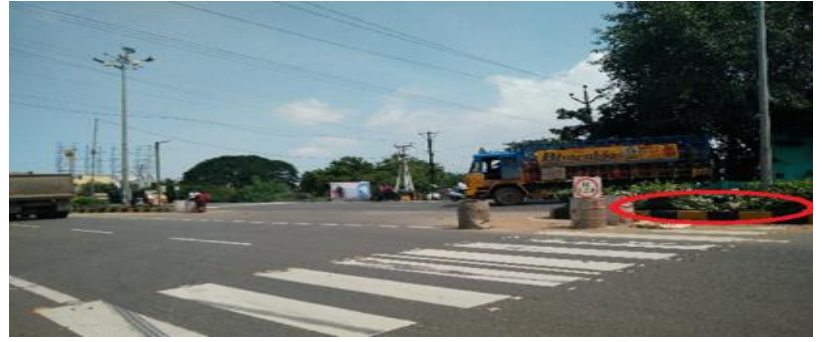

Fig.14: at chainage: $264.870 \mathrm{~km}$ RCW.

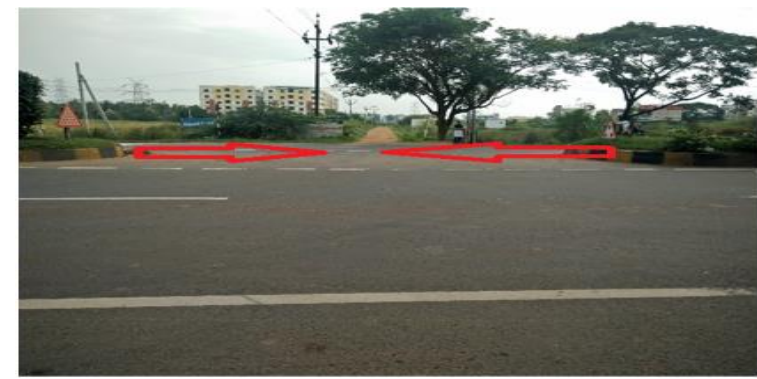

Fig.15: at chainage: $264.608 \mathrm{~km} \mathrm{RCW.}$

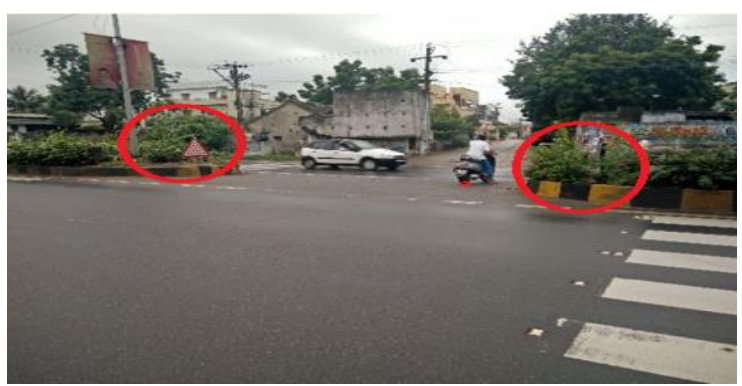

Fig.16: at chainage: $262.427 \mathrm{~km} \mathrm{RCW}$.

In the figures 15,16 there is no shelter lane provided near the gap in median.

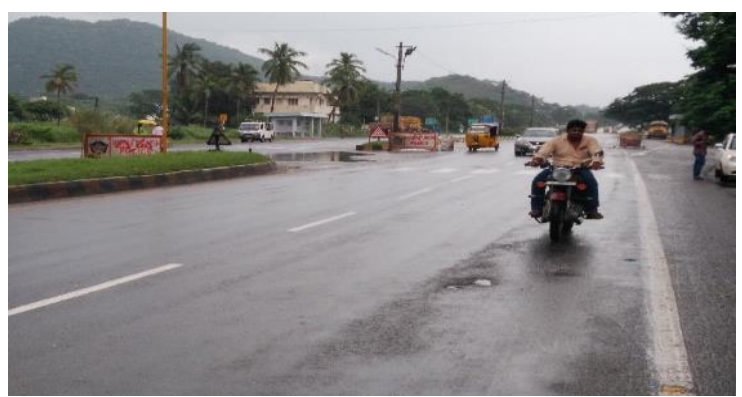

Fig.17: at chainage:256.125km RCW.

In the figure-17 there is no proper drainage facility as the rain water stagnant at gap in median.

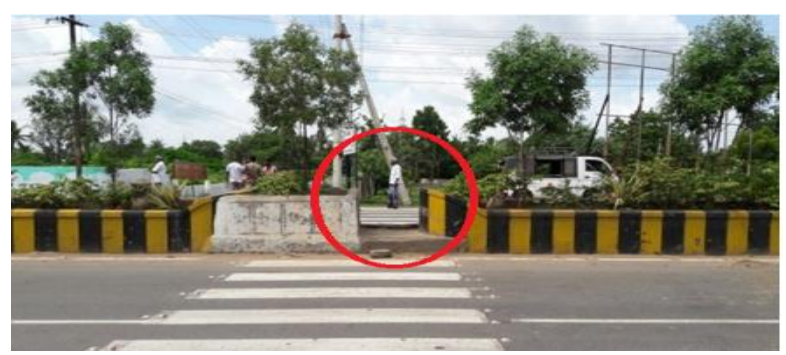

Fig.18: at chainage: $268.817 \mathrm{~km}$.

In the figure-18 un-authorized gap in median is provided for the pedestrians.

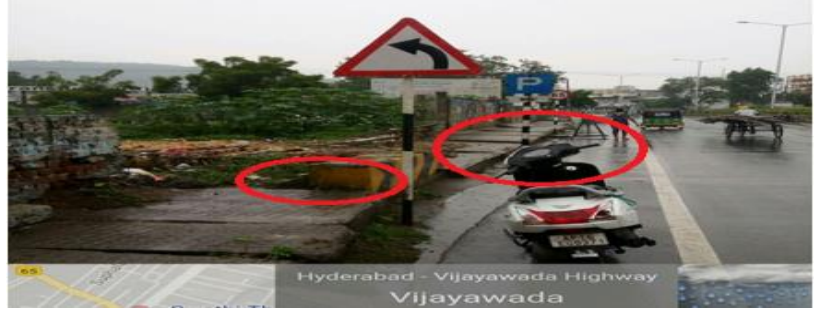

Fig.19: at chainage: $269.557 \mathrm{~km}$. LCW

In the figure19 though there is parking sign facilities are not provided for the parking.

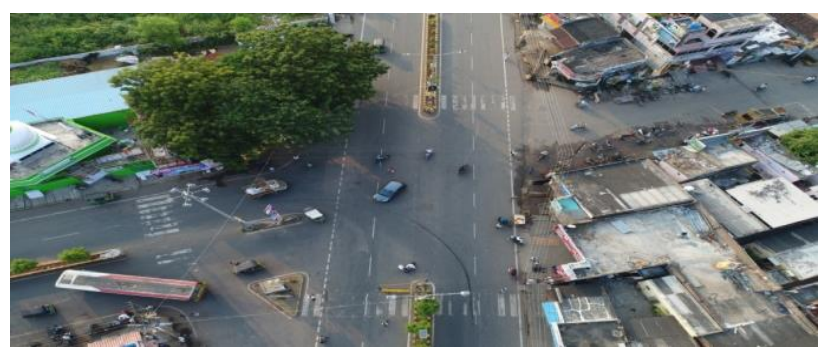

Fig.20: at chainage: $269.528 \mathrm{~km}$.

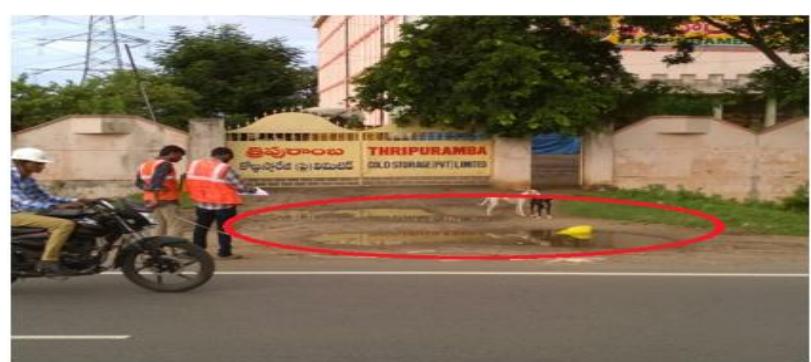

Fig.21: at chainage: $260.921 \mathrm{~km} . \mathrm{RCW}$

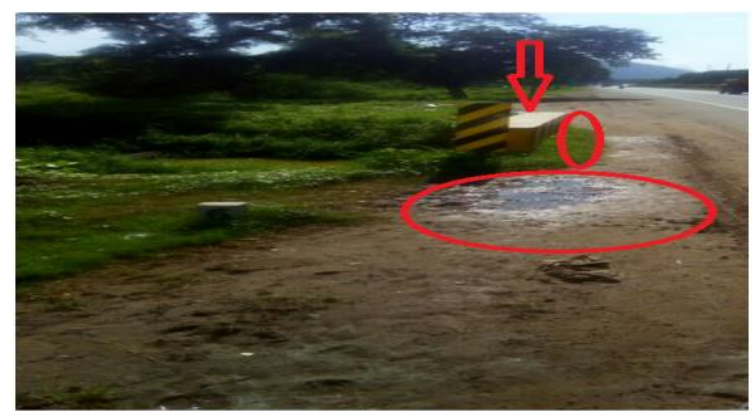

Fig.22: at chainage: $254.605 \mathrm{~km} . \mathrm{LCW}$

In the figure-21,22 the earthen shoulder is damaged due to the water stagnation proper drainage has to be provided.

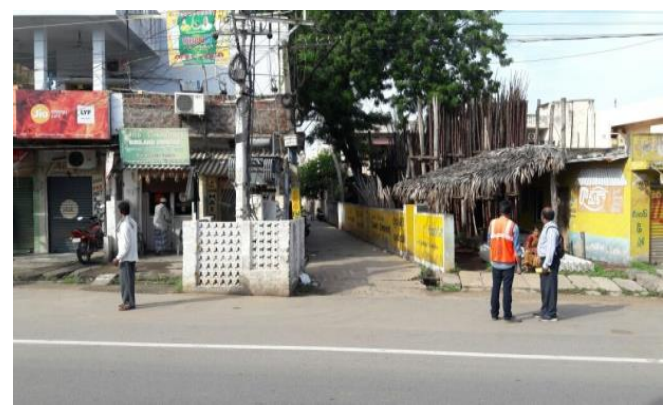

Fig.23: at chainage: $269.260 \mathrm{~km}$. RCW 


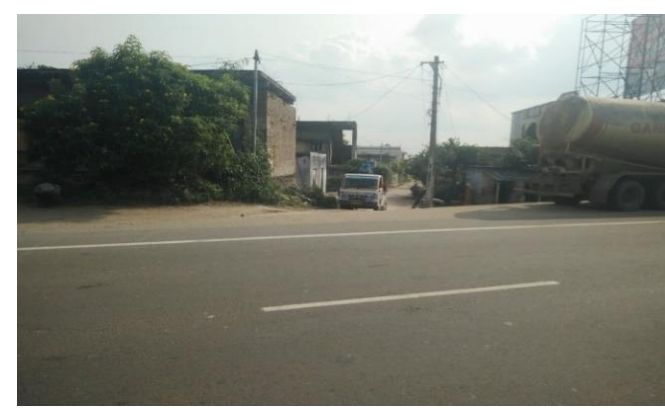

Fig.24: at chainage: $254.017 \mathrm{~km} \mathrm{RCW.}$

In the figure 24 there is no proper approach provided on to the $\mathrm{NH}$, the approach road is very steep.

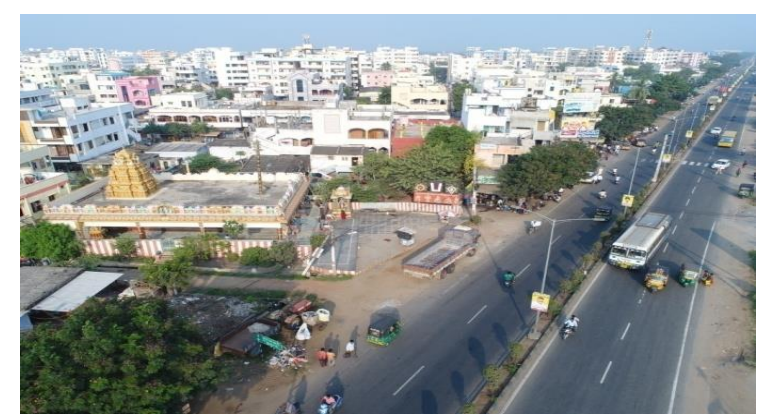

Fig.25: at chainage: $267.193 \mathrm{~km}$.

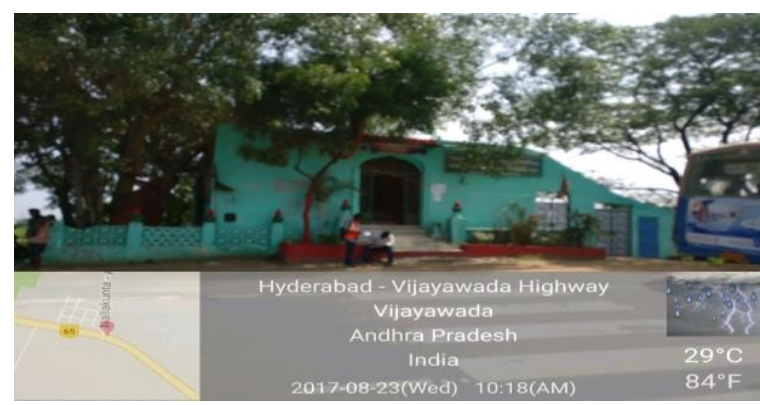

Fig.26: at chainage: $264.910 \mathrm{~km}$. LCW

In the figures 25,26 the pilgrimages are on the side of the $\mathrm{NH}$ without any parking facilities which are causing obstruction to the flow of traffic.

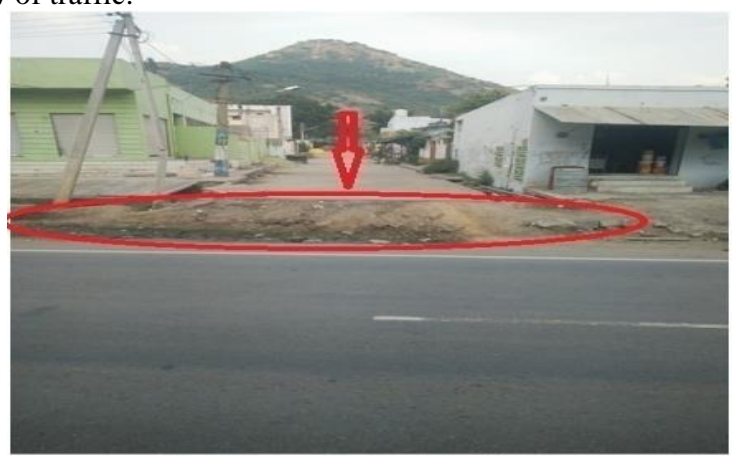

Fig.27: at chainage: $247.915 \mathrm{~km} . \mathrm{LCW}$

In the figure-27 the approach to the $\mathrm{NH}$ is not provided it has to be laid.

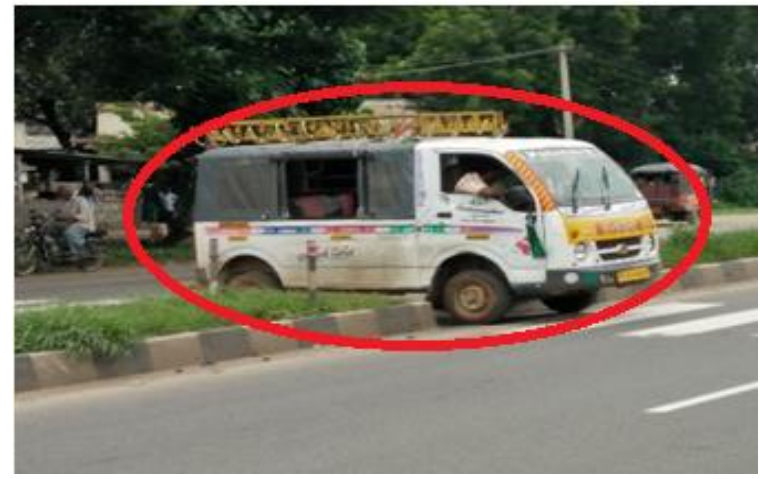

Fig.28: at chainage: $250.939 \mathrm{~km}$

In the figure-28 there is an un-authorized gap in median in-front of the Z. P. H school, Mulapadu village where the vehicles are using it to change the lanes which can cause accidents

\section{Conclusions}

Based on this case study on the four-lane national highway- 65 [previously NH-9] the following conclusions have been drawn

From the four lane National Highway-65 i.e., from $247.650 \mathrm{~km}$ to $270.340 \mathrm{~km}$, by analysing the information it is found that road markings, condition of shoulder, condition of carriageway and median opening are the factors for causing accidents on the $\mathrm{NH}$ 65. It also observed that the moderately moving vehicular traffic is generating traffic problems for the fast moving vehicular traffic as it generally occupies innermost lane of national highway. Along this four lane national highway, service roads need to be provided so as to isolate slow moving vehicular traffic from fast moving vehicular traffic.

All the unauthorized gap-in-median should be closed and necessary provisions like foot-over bridges to be provided for the local neighbourhood to cross the national highway on the priority basis. All undeveloped minor and major crossings should be developed with necessary lighting provisions such that the accident rate can be decreased along the surveyed areas.

Footpath for the pedestrian need to be developed near the habitant areas, industries, educational institutions and to be properly maintained wherever it is there and also the guard rail need to be provided along the entire length of the footpath. Facilities for the differently abled people at bus stops need to be developed on the NH-65.

\section{Acknowledgement}

We are thankful to the Government of Andhra Pradesh for giving us the opportunity to audit the NH-65 regarding the safety aspect. We are also thankful to the faculty and non-teaching staff of Department of Civil Engineering, V R Siddhartha Engineering College for their co-operation towards the Road Safety Audit of NH-65. We would like express our gratitude to Mr G Bhogayya Naidu, Mr P Suresh Asst Professor, Department of Civil Engineering, and VRSEC for continuous support and help during the course of work.

\section{References}

[1] "MORTH SPECIFICATIONS 5th revised edition".

[2] "MANUAL ON ROAD SAFETY AUDIT", IRC-SP- O882010.

[3] “CODE OF PRACTICE FOR ROAD MARKINGS”, IRC-SP035-2015.

[4] "Road safety audit for four lane national highways", Dr. S. S. Jain, P.K. Singh, Dr. M. Parida.

[5] "Road safety and road safety audit in india: a review", Abdul Rahoof M. Tech Scholar, Bipin Kumar Singh, Head of Depart- 
ment Civil Engineering Department, NIMS University Rajasthan, India

[6] "Road safety audit", Arun S Bagi Department of Civil Engineering, Dayananda Sagar College of Engineering, Bengaluru, Dheeraj N Kumar; Visvesvaraya Technological University, Belgaum, India.

[7] "Road safety audit: a case study for wardha road in nagpur city"; Manish.D. Katiyari, Prof.S.D. Ghodmare, M-Tech (Trans Eng, Research Scholar). 